\title{
Design and Thermal Performance Analysis of Shell and Tube Heat Exchanger by Using CFD-A Review
}

\author{
Gajanan P Nagre ${ }^{1}$, A. V. Gadekar ${ }^{2}$ \\ ${ }^{1}$ Department of Mechanical Engineering, MGM'S Polytechnic, Aurangabad \\ ${ }^{2}$ Department of Mechanical Engineering, Professor at MIT Engineering, Aurangabad
}

\begin{abstract}
This paper is concerned with the study of shell and tube heat exchanger. Also the factors affecting the performance of shell and tube heat exchanger is studied and its details discussion is given. this paper focuses on the designing of small shell and tube heat exchanger with counter flow arrangement. Thermal analysis is carried out considering various parameters such as baffle spacing, baffle inclination, flow rates of hot and cold fluids, tube diameter etc. by using CFD. Some research papers are studied in details and then review from those papers is described in the paper.
\end{abstract}

Keywords: STHE-Shell and Tube Heat Exchanger, CFD- computational fluid dynamics, flow rate, baffle spacing, baffle inclination

\section{Introduction}

Heat exchangers are devices that facilitate the exchange of heat between two fluids that are relatively at different temperature while keeping them from mixing with each other. heat exchanger is used to transfer heat between two or more fluids that are at different temperature separated by solid wall. The wall may be simple plane wall or tube or complex configuration involving fins, baffles and multi-pass tube. Purpose of heat exchanger is either cool or heat the desired fluid. Shell and tube heat exchangers have been most widely used equipment in the industrial fields including refrigeration and air conditioning system, power plant, petroleum refining, steam generation etc. baffle spacing, baffle inclination, number of tubes, tube diameter are the main factors affecting the performance of shell and tube heat exchanger. Design of shell and tube heat exchanger is based on correlation between kern method and Bell-Delaware method. Desirable feature of heat exchanger would be to obtain maximum heat transfer with least operating cost and low pressure drop with high value of heat transfer coefficient.

\section{Shell and Tube Heat Exchanger}

As its name implies, this type of heat exchanger consist of shell (large pressure vessel) and large number of tubes (sometime several hundred) packed in shell with their axes parallel to that of shell. Heat transfer takes place as one fluid flows inside the tube while the other fluid flows outside the tubes through shell. Shell and tube heat exchangers are further classified according to number of shell and tube passes involved. Basic components of shell and tube heat exchangers are tube, tube sheet, shell and shell side nozzle, channel covers, baffles etc. Typical parts and their arrangement are shown in fig 1.

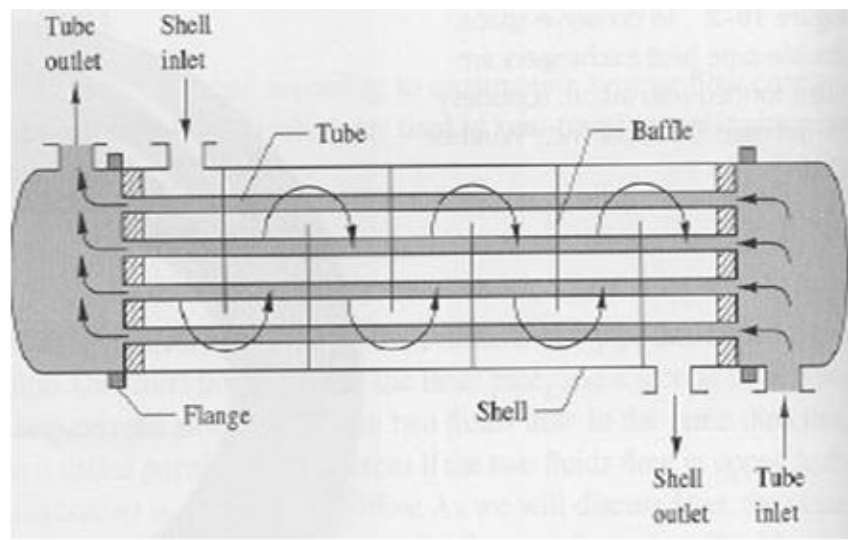

Figure: Shell and tube heat exchanger

\section{Factors Affecting the Performance of Shell and Tube Heat Exchanger}

For a given shell geometry, the ideal configuration depends on the baffle cut, the baffle spacing, and baffle inclination angle. Even after fixing the right baffle cut and baffle space the performance can be still improved by varying baffle inclination angle. Having lower inclination angle, increases heat transfer at the cost of increased shell side pressure drop. On the other hand increasing angle beyond value might result in reduced pressure drop but with lesser heat transfer. So it is very important to have an optimum baffle angle to give minimum pressure drop with maximum heat transfer. Also determining effective baffle spacing and tube diameter for optimum baffle inclination.

\section{Computational Fluid Dynamic}

CFD technique can be used both in rating and iteratively in achieving the optimum combination of baffle arrangement for shell side. CFD is particularly useful during initial design steps, reducing number of testing of prototype and providing a good insight in the transport phenomenon occurring in the heat exchanger. CFD resolve the entire system in the small cells and apply governing equations on these discrete elements to find numerical solution regarding pressure 


\section{International Journal of Science and Research (IJSR) \\ ISSN (Online): 2319-7064}

Index Copernicus Value (2013): 6.14 | Impact Factor (2014): 5.611

distribution, temperature gradient. Software will provide with images and data which predict the performance of that design.

Basic approach to using to CFD;

1) Pre-processor: establishing the model

a) Prepare the geometry of heat exchanger model using CAD tools

b)Create computational mesh in the flow domain

\section{2) Solver}

a) Apply the boundary conditions

b) Solve the governing equation on computational mesh using analysis software

\section{3) Post processor: interpreting the results}

a) Interpret the prediction to determine design iteration as possible solution if needed.

\section{Objective of Paper}

Objective of this CFD study is to investigate impact of various baffle inclination angle on fluid flow and heat transfer characteristics of shell and tube heat exchanger using CFD. Optimum baffle angle is desired to give minimal pressure drop with maximum heat transfer.CFD simulation will be carried out for different baffle inclination and determining effective baffle inclination and the results i.e. pressure drop, temperature, heat transfer coefficient and effectiveness are find out for designing small shell and tube heat exchanger and comp airing these results with Kern and Bell-Delaware methods for best design of shell and tube heat exchanger.

\section{Design Data for Shell and Tube Heat Exchanger}

Before discussing actual thermal design, let us look at the data that must be finished by the process licensor before design can begin

1) Flow rates of both streams

2) Inlet and outlet temperature of both streams

3) Operating pressure of both stream. This is required for gases especially. It is not really necessary for liquids, as their properties do not vary with pressure.

4) allowable pressure drop for both stream. This is very important parameter for heat exchanger design. Generally liquid a value of $0.5-0.7 \mathrm{~kg} / \mathrm{cm}^{2}$ is permitted per shell. For gases allowable value is generally $0.05-0.2 \mathrm{~kg} / \mathrm{cm}^{2}$ with $0.1 \mathrm{~kg} / \mathrm{cm}^{2}$ being typical.

5) Physical properties of both streams these include viscosity, thermal conductivity, density and specific heat preferably at both inlet and outlet

6) Preferred tube size: tube size is designated as outer diameter $\mathbf{x}$ thickness $\mathbf{x}$ length

7) Maximum shell diameter: floating head heat exchangers are often limited to shell inside diameter of $1.4-1.5 \mathrm{~m}$ and tube length of $6 \mathrm{~m}$ or $9 \mathrm{~m}$. Whereas fixed tube sheet heat exchanger can have shell as large as $3 \mathrm{~m}$ and tube length up to $12 \mathrm{~m}$ or more.

8) Material of construction: if the tubes and shell are made of identical materials all the components should be of this material. Thus only the shell and tube materials of construction need to be specified

\section{Literature Review}

Yusuf Ali Kara, Ozbilen Guraras: prepared computer based design model for preliminary design of shell and tube heat exchanger with single phase fluid flow both on shell and tube side. The program determines the overall dimensions of shell tube bundle and optimum heat transfer surface area required to meet the specified heat transfer duty by calculating minimum or allowable shell side pressure drop. He concluded that circulating cold fluid in shell side has some advantages on hot fluid as shell stream since former causes lower shell side pressure drop and requires smaller heat transfer area than the latter and thus it is better to put the stream with lower mass flow rate on shell side because of baffle space.

Sandeep K. Patel, Alkesh M. Mavani: purpose of this paper is how to design the shell and tube heat exchanger which is majority type of liquid to liquid heat exchanger. General design consideration and design procedure are also illustrated in this paper.in design calculation s HTRI software is used to verify manually calculated result.

Su Thet Mon Than, Khin Aung Lin Mi, Sandar Mon: in this paper data is evaluated for heat transfer area and pressure drop. Primary aim of this design is to obtain high heat transfer rate without exceeding the allowable pressure drop. Gradual decrease in Reynolds means there is significant decrease in pressure drop respectively.

Usman Ur. Rehman: had investigated an un-baffled shell and tube heat exchanger design with respect to heat transfer coefficient and pressure drop. Numerically modeling the flow and temperature fields are resolved using commercial CFD package and it is performed for single shell and tube bundle and is compared with experimental result. Heat transfer is found to be poor because the most of shell side fluid by-pass the tube bundle without interaction. Thus design can be modified to achieve the better heat transfer in two ways either the shell diameter is reduced or tube spacing can be increased.

Apu Roy, D.H.Das: present work has been carried out with view to predicting the performance of shell and finned tube heat exchanger in the light of waste heat recovery application. By considering different heat transfer fluids the performance of above heat exchanger can also be predict. The performance parameters of heat exchanger such as effectiveness, overall heat transfer coefficient, energy extraction etc. have been taken in this work.

Sunilkumar Shinde, Mustansir Hatim Pancha: the paper consist of thermal analysis of heat exchanger with helical baffles using Kern method. This has been modified to approximate result for different helical angles. Helical baffles heat exchanger eliminates principle shortcoming in conventional heat exchanger due to shell side zig zag flow, induced by segmental baffle arrangement flow pattern. In the 
shell side of continuous helical baffle heat exchanger is rotational. This flow pattern result in significant increase in heat transfer coefficient.

Kirubadurai.B, R.Rajasekaran, K.Kanagaraj, P.Selvan: general design consideration and design procedure are illustrated in this paper. The analysis of orifice baffle and convergent and divergent tube in shell and tube heat exchanger are experimentally carried out the newly designed heat exchanger obtained a maximum heat transfer coefficient and lower pressure drop. From the numerical experimentation result shows that the performance of heat exchanger increases in modified baffle and tube than segmental baffle and tube arrangement.

\section{Conclusion}

CFD can be used as design tool in the preliminary stage of design of shell and tube type heat exchanger. In this review paper shell and tube heat exchanger model is designed by using CFD. Thermal performance analysis for shell and tube heat exchanger can be done by measuring various parameters through CFD software. CFD design results for shell and tube heat exchanger can be compared with theoretical design results by using Kern and Bell Delaware methods.

\section{References}

[1] Sandeep K.Patel, Alkesh M.Mavani, shell and tube heat exchanger thermal design with optimization of mass flow rate and baffle spacing, IJAERS/Vol.II/Issue I/Oct-Dec 2012.

[2] Sunil K.S. and Pancha M.H., Comparative thermal performance of shell and tube heat Exchanger with continuous helical baffle using different angles, International Journal of Engineering Research and Applications, 2(4), 2264-2271 (2012).

[3] Thirumarimurugan M., Kannadasan T. and Ramasamy E., Performance Analysis of Shell and Tube Heat Exchanger Using Miscible System, American Journal of Applied Sciences, 5, 548-552 (2008).

[4] Usman Ur Rehman, Heat Transfer Optimization of Shelland-Tube Heat Exchanger through CFD Studies, Master's Thesis in Innovative and Sustainable Chemical Engineering, G" oteborg, Sweden, 13-14, 2011.

[5] Yusuf Ali Kara, Ozbilen Guraras, "A computer program for designing of shell and tube heat exchanger", Applied Thermal Engineering 24(2004) 1797-1805

[6] Sunilkumar Shinde, Mustansir Hatim Pancha "Comparative Thermal Performance Analysis Of Segmental Baffle Heat Exchanger with Continuous Helical Baffle Heat Exchanger using Kern method. International Journal of Engineering Research and Applications (IJERA), July-August 2012.

[7] Jian-Fei Zhang, Ya-Ling He, Wen-Quan Tao1, A Design and Rating Method for Shell-and-Tube Heat Exchangers With Helical Baffles, School of Power and Energy Engineering, Xi'an Jiaotong University, Xi'an 710049, China.

[8] Holman, J.P. (2004) Heat Transfer, $9^{\text {th }}$ Edition, Tata McGraw-Hill, Inc., New York. 